\title{
Towards Zoomocracy - an Explorative Study on Virtual Democratic Decision Making in Swedish City Council Meetings in the Wake of the Covid- 19 Pandemic
}

\author{
Agneta Blom \\ Örebro University \\ agneta.blom@oru.se
}

\author{
Fredrik Carlsson \\ Linköping University \\ fredrik.carlsson@liu.se
}

\author{
Elin Wihlborg \\ Linköping University \\ elin.wihlborg@liu.se
}

\begin{abstract}
Governmental decision making is essential to maintain democracy. The decision making formats and processes are institutionalized and follow strict formats for participation, debate and decisions. The constraints and lock-downs due to the covid-19 pandemic led to an extensive increase in the use of digital meeting tools to maintain democratic decision making through virtual meetings. Our main approach in this paper is to inductively explore the changes that occur when democratic meetings take place on-line through a quantitative text analysis and interviews. We delimit our focus to speech duration in recorded meetings. We find that the virtual meeting format changed meeting characteristics compared to on-site meetings. There were some changes in speech duration among councilors which has to be further investigated in a larger sample. The main contribution of this paper is the method to measure actual speech duration and compare how virtual meetings may influence the organization of democratic meetings.
\end{abstract}

\section{Introduction}

When the covid-19 pandemic became global in early 2020, national governments, companies and local governments had to reconsider the format and content of decision making meetings. This led to a rapid growth of virtual meetings [1]. Virtual meetings offered a solution for society, including elected governmental bodies, to meet and make decisions collectively whilst maintaining social distance, thus hindering the spread of covid-19. This rapid transformation from on-site to on-line meetings has neither previously been seen as a format nor a means of digital government. Furthermore, online meetings have not been addressed in previous research on digital government. Providing results in the form of decisions is one important purpose of meetings [2]. However, the meeting institution (the format, processes, means, and procedures leading to the decision) is also important for collective decision making in the public sector [2]. It can be argued that it is a central purpose for these institutions to provide democratically made decisions. The meetings are often institutionalized by laws, policies, and practices in order to promote democratic values [3]. Meetings can be understood not only as instrumental to achieving something outside of the meeting itself, but that meetings constitute an essential part of what modern organizational leadership is expected to be all about [2]. Coming together and solving common problems are at the core of democratic decision making. Thus, the meeting plays a key role in democratic decision making and to thereby uphold legitimacy for public governance [3].

Meetings symbolize leadership and organization, create decisions and governance, inform, organize, and achieve coordination [2]. The strive for deliberative understanding, coordination and search for consensus making constitutes one important outcome from public meetings, as has been particularly noticed in studies of involvement of stakeholders [4]. In a parliamentary setting, delivering speeches is one of the main meeting activities. Despite this, previous research on the role and impact of speaking in democratic meetings is scarce. In a study of MP's activities in the Czech parliament Marcinkiewicz and Stegmaier [5] found that the more frequently individual legislators deliver speeches in the parliament, the better their electoral performance. They call for more attention to the role and effects of speeches [5].

Meetings in local government councils are in most countries the decision making bodies closest to the citizens and their daily issues. Local governments are key actors for delivering local services and infrastructures in most democracies, even if they have slightly different competences [6]. In this article we focus on Sweden, where local governments have a large capacity and degree of autonomy and function in welfare provision [7]. 
In times of constraint due to the covid-19 pandemic most meetings have been transferred to virtual on-line meetings, including local democratic decision making meetings. But what happens with democratic decision making when the meetings are transformed from onsite to on-line and when this occurs rapidly? Since many local government on-site meetings in Sweden have already been streamed and broadcasted, there are openings to evaluate and compare differences in how meetings are arranged and who speaks. In this paper, we explore how virtual local council meetings are organized and who speaks compared to on-site meetings in the same local council from one year ago. We focus specifically on the method used to measure speech duration among different age groups to elaborate on the effects of a potential digital divide.

\subsection{Aim of the Paper}

Since the covid-19 pandemic struck the world in 2020, local government council meetings in Sweden switched from on-site meetings to on-line meetings [8]. The local democratic governance is institutionalized through the meeting procedures of local government councils. It is, therefore, relevant to shed light on the impact of virtual council meetings.

This paper aims to present an explorative method and analysis of how local government council meetings in Sweden changed due to the use of new digital tools during the Covid-19 pandemic. This will facilitate the analysis and discussion of the impacts of virtual meetings on distribution of speaker time and organization of the meetings. The purpose is both to explore the new virtual council meeting arena inductively and to discuss implications of the method of measuring speech duration.

\section{Framing Local Self-Government in Sweden - Background}

Local self-government in Sweden has a long tradition and was legislated in 1862. In the portal clause of the Swedish constitution the municipal selfgovernment is established as fundamental to Swedish democracy ${ }^{1}$. In this section we present the context and setting for the associated digitalization of meetings.

\footnotetext{
${ }^{1}$ Comprehensive information on local governments in Sweden are presented on the following home page from SALAR (Swedish Association of Local Authorities and Regions) Municipalities and regions | https://skr.se/skr/tjanster/englishpages.411.html (Visited May 28, 2021).
}

\subsection{Institutional Framing of Local Governments}

At present, Swedish local governments are organized in 290 municipalities and 21 regions $^{2}$. Together these have an extensive responsibility for providing welfare services. Of the total public expenditure in Sweden, 49 percent concerns the local government sector and 83 percent of all public sector employees are employed in local governments. The 2012 Eurobarometer indicated that 65 percent of the Swedes have high trust in local and regional government [9, 10].

The municipalities handle primary and secondary education for children, care for children and elderly, and social welfare services. The municipalities also provide services such as water and sewerage, parks and recreation, fire protection, culture, and leisure. The regions are responsible for regional development at large in their geographical area. They also provide primary and hospital care, dental care, and in cooperation with the municipalities are responsible for regional public transport [7].

The councilors are elected by the constituents in public elections every fourth year. The election system is proportional and based largely upon a national leftright party system. Local parties are growing [11]. The public trust in local government is expressed through the high turnout in local council elections [12]. Both local and national parliament elections are held at the same time every fourth year and approximately two thirds of the voters make an independent act of choice in the local elections (municipal and regional) in relation to the national election [13].

The number of members in the 310 local government councils varies between 21 and 101 councilors in regards to respective local population size. There are a total of 7,611 elected councilors including deputies. The size of each council affects how the meetings are organized. [14].

\subsection{The Decision Making Context in Local Governments}

The local government council is the highest decision making body in municipalities and regions and they are responsible for decisions regarding budget, local taxes, and the founding of and overall plans for the direction, scope and quality of municipal activities. They are responsible for electing members and deputies to the municipal executive board and

\footnotetext{
${ }^{2}$ One municipality counts as both a region and municipality, which means there is a total of 310 local governments, each with its own council.
} 
committees, and to elect auditors who review the operations. The council also monitor financial outcomes and decides on discharge from liability for the executive board and committees. The local government councils are thus vital to the functioning of the Swedish welfare services and must make decisions in a democratically regulated manner as stipulated by the law to ensure this functioning [7].

The council meetings are essential for both the welfare services and for the democratic system. The local government council meeting is the only municipal decision making meeting open for the public, as stipulated by the Municipal Act. This makes it the only democratic institution where citizens can listen and watch local political debate and speak to local government councilors gathered on-site [15]. In 2014, about 70 percent of the councils had implemented a legal act giving citizens the opportunity to write proposals directly to their council $[16,17]$.

The local government council is led by the chair of the council and their role is regulated by the Municipal Act. The Act also provides the main structure for the work in the council and how to reach democratic transparency [18]. The chair's primary task is to lead the council meetings, set the agenda for the meetings and to summon the council. Although the chair is elected by and amongst the council, often being part of a political party and having the political competence like any other councilor, the role is also administrative in the sense that it is expected that the chair focus on leading the council meeting, thus not engaging in debate. The chair can delegate tasks and often works closely together with the presiding committee. The 310 local governments have different administrative resources backing up the council meetings, such as secretaries and technicians, depending on size [15].

\subsection{The Pandemic Digitalization of Local Government Council Meetings}

In 2014, national legislation made it possible for each council to decide on and implement rules on digital participation in the council meetings. The purpose of the legislation was to enhance incentives for participation from marginalized groups in the city council such as people with disabilities and single parents [16, 18, 19]. An evaluation from a national governmental committee in 2016 showed that merely four percent of the municipalities had implemented rules for digital participation [19]. Thus, before the covid-19 pandemic, the vast majority of council meetings were held with all council members on-site

\footnotetext{
${ }^{3}$ SALAR stands for Swedish Association of Local Authorities and Regions. They represent and advocate local government interests and speak for all municipalities and regions with the
}

and the opportunity to use digital meeting formats were rare. According to a survey by $\mathrm{SALAR}^{3}$ in January 2021, 89 percent of the municipalities and 94 percent of the regions had implemented rules allowing for digital participation, thus enabling virtual meetings. Furthermore, 69 percent of the municipalities and 76 percent of the regions had tried meetings with councilors participating digitally at least once [17].

Major changes done to manage the council meetings in the wake of the covid-19 pandemic during 2020 were decided and handled by the municipalities and regions themselves. This included cancelling meetings, limiting meeting agendas or even blocking citizen access to council meetings, lowering the size of local government councils or moving to larger meeting facilities. There was a subsequent impact upon both the meetings and the democratic legitimacy [20, 21].

Cancelling council meetings was not seen as a sustainable solution, by any of the interviewed municipal council leaders. Instead, most municipalities developed strategies to arrange full digital meetings or on-line participation for some of the members. There were discussions on how to manage the council meetings amongst councilors when they found out that the pandemic constraints were to remain for an unknown period of time [20]. A virtual conference was arranged by SALAR in April 2020 to discuss and coordinate local management of the council meetings. One of the keynote speakers, a council chair, said:

$$
\begin{aligned}
& \text { It is only to state that we started } \\
& \text { when the pandemic struck by } \\
& \text { cancelling a council meeting, then } \\
& \text { we said that this will not work, so } \\
& \text { we drove hard right away by saying } \\
& \text { that we have to go digital. }
\end{aligned}
$$

If digital participation was more of a policy targeted at lowering participation thresholds for certain groups before the covid-19 pandemic (and only implemented by a handful of municipalities), it quickly became a democratic necessity for the local government councils to implement.

\subsection{Openings for Legitimate Decisions-Making in Digital Meetings and our Research Approach}

The preparatory inquiries for the revised Municipal Act, which allowed for digital participation, described digital participation as a complement to physical

Swedish government, Swedish agencies and the EU. See: https://skr.se/skr/tjanster/englishpages.411.html 
meetings [18]. This mode has come to be referred to as "hybrid-meetings" whereby some participate in the on-site meeting and some through digital meeting tools whilst in the same meeting. During the covid-19 pandemic, local government councils in Sweden tried different types of set-ups including hybrid meetings. These were deemed by many chairs as more difficult to lead [17]. The changes due to the covid-19 pandemic have in many respects changed everyday life activities, as well as more formal and governmental organizational practices. Changed behavior due to the Covid-19 pandemic has in previous research been analyzed from a timegeographical perspective and results show both altered use of time and activity patterns [22]. This points to the need to focus on time use and potential consequences.

Previous research has shown that senior people have more difficulties using a computer than those who are younger [23, 24]. Some literature has highlighted a digital divide between young and old rooted in computer skills [23]. Another line of previous literature on political participation, scholars have noted higher passivity among youth citizens, which increasingly seem to avoid more traditional forms of political participation such as voting in general elections, becoming a member of a political party, and participation in activities in associational life [25].

This raised the issue of whether older councilors having trouble using a computer compared to younger ones may result in them also having trouble speaking up in virtual meetings. If so, this may lead to a lower speech duration relative to the younger councilors.

The ambition in this paper is to analyze how the digitalization of local government council meetings influences the meeting management when it comes to speaking time and organization of the meetings. In this initial explorative analysis, we focus on the organization of the type of subject matters discussed.

Secondly, we discuss how age influences the speech time in the council, based on the hypothesis that younger councilors would more easily adapt to the new digital meeting context and therefore speak more.

\section{Research Design and Methods}

Based on the situation that occurred due to the pandemic-based constraints where most local government council meetings in Sweden took place on-line, we found a unique opportunity to analyze the impacts of on-line meetings. In councils where the meetings had already been broadcasted on-line and recorded before, there were unique openings to collect data to compare on-site and on-line meetings.

\subsection{Selected Sases - "Pine City" and "Oak City"}

When selecting units of analysis, the selection of two different councils were discussed with regards to geographical location, positioning on the left-right scale, and meeting culture.

This gave us two local government councils with different contexts and cultures, but with similarly sized populations and local government councils. It was deemed important to find councils with different deliberative councils. One of the co-authors has a long experience of working with the local government councils allowing in-depth knowledge and therefore a strategic choice in the selection of councils to fulfil these criteria.

Larger municipalities were examined to find council meetings that were more structured, formalized and with professional support available for interviews. This would also naturally increase the potential variation of different councilors speaking. Additionally, the selected municipalities had implemented the legal act to allow for use of digital participation in council meetings. We gave the selected municipalities the symbolic names "Pine City" and "Oak City", which we use throughout this paper to maintain anonymity.

\subsection{Analyzing Recorded Videos of Council Meetings}

In the two local government councils we then strategically selected four council meetings - two in each municipality in January 2020 and January 2021. In January 2020, Covid-19 had not yet effected Swedish health polices and the council meetings were held without any virtual present councilors whilst still being filmed and thus opening up for comparison. In January 2021, Pine City had previously conducted one virtual council meeting a month earlier and Oak City had conducted two virtual meetings. The recordings of the council meetings are accessible online for the public in an edited broadcast version. The municipal administration sent us the raw video files of the meetings. The raw versions contained the same view, sound, and camera angles as the publicly available broadcasted version of the council meetings, but with the addition of some minor editing in pauses and graphics. These files were loaded into the text-analysis software NVivo for processing and analysis.

We watched each meeting two times. The first time being an overall assessment of the meeting while taking notes and tagging interesting periods. During the second round, we watched the meetings in detail. We coded who spoke and used NVivo's built-in timer to record speech duration for every time someone 
started speaking while having the floor in the meeting or if members of the preceding committee, who lead the meeting, said something without having the floor. Since all council meetings in Sweden follow an order where only one person at a time is allowed to speak in the council (not including whispers between councilors), it makes recording speech duration very accurate. To minimize reliability errors in speech duration we estimated a maximum of one second error margin per speech, which is just over one percent of the average speech duration. Speech duration for each occasion was measured from the moment the speaker started to speak to the moment the speaker ended their speech. We did not include the time to walk to-andfrom the podium nor silences before or after the speaker started or ended their speak. Furthermore, we coded body language, rhetorical techniques, appearance, background in the virtual meetings, and the overall characteristics of the speech - for instance, if the speaker seemed calm, engaged and to what extent the speaker read from a note or spoke freely.

In total we used eight categories to categorize the activities in the four meetings. A total of 646 rows were coded for the four meetings according to speech rhetoric, start time, end time, type of subject matter, and topic, among other variables. This resulted in 3,230 manually coded cells before processing the data. Additionally, we included both background variables regarding the meeting and the councilors.

\subsection{Processing the Recorded Council meetings Data Set for Analysis}

To analyze the data, we first checked for reliability errors and robustness, and then constructed variables as described below. In this paper we use speech duration focused on type of subject matter and age. Age was coded into ten-year brackets e.g., if a councilor was 35 years old at the time of the meeting then they were given the label "30-39". In quantitative measurement terms re-coding into age brackets can be interpreted as going from ratio age measurements to interval age measurements [26]. Using interval age measurements could help link our findings to theory but could also potentially cause unwanted issues. For instance, since there is a year between the meetings 2020 and 2021, some councilors might "jump" up an age group in the 2021 meeting compared to the 2020 meeting and thereby impact the analysis in a more dramatic way than the actual one-year age jump would have had using a ratio measurement. However, the severity of this particular issue decreases as the number of meetings and cases increases [26]. In this study, we checked for these "jumps" and it did affect the Pine City meetings but not the Oak City meetings.
This made us reflect upon our findings and the effects of similar issues on method are further discussed in relation to our conclusions.

\subsection{Relative Speech Duration}

Since council meetings vary in length, we needed to construct a measure that would allow for comparison between meetings. Thus, the results below are presented as relative speech duration. The relative speech duration measure returns a decimal between 0 and 1 for each councilor which represents the councilors share of the total speech duration during a meeting. The measure was constructed by totaling each councilor's total speech duration during a meeting. This gave us a total time measure for each councilor stretching from zero to often over an hour for the chair. We excluded the chair from our analysis, unless otherwise stated, since the chair themself is not involved in the debate but rather lead it.

We summed up the total speech duration for all councilors and then divided each speech entity with the total speech duration. This gave us a relative measure of speech duration for each entity as a percentage of the total speech duration of the meeting. For example, if the total meeting length was five hours, total meeting speech duration was four hours, and one councilor had a total speech duration of one hour, then that councilor had 25 percent of the total speech duration in the meeting.

\subsection{Interviews}

The analysis of the recorded meetings occurred parallel to the planning of the interviews, including the construction of the interview guide used in the four interviews. The construction of the interview guide was somewhat of an abductive process in the sense that the data from the recorded meetings were interpreted and re-interpreted in the light of theory and analysis of data from previous interviews by the authors on similar topics [27].

We have described the role of the chairs but not the secretaries of local government councils. The secretary role is not regulated by law and often has slightly different functions depending on the specific council. Nonetheless, councils need secretaries. They are municipal officers and they commonly act as support in writing the meeting protocol and helping the chair administrate the meeting before, during and after. Thus, council secretaries could provide valuable input about the meetings. 
Table 1: Interviewed

\begin{tabular}{|c|l|l|}
\hline $\begin{array}{c}\text { Position of } \\
\text { interviews person }\end{array}$ & \multicolumn{1}{|c|}{ Oak City } & Pine City \\
\hline Chair & $\begin{array}{l}\text { IP1, Man, Age } \\
\text { 59, The Center } \\
\text { Party }\end{array}$ & $\begin{array}{l}\text { IP2, Woman } \\
\text { Age 52, The } \\
\text { Social } \\
\text { Democrats }\end{array}$ \\
\hline Secretary & $\begin{array}{l}\text { IP3, Woman } \\
\text { Age 27, } \\
\text { municipal officer }\end{array}$ & $\begin{array}{l}\text { IP4, Woman } \\
\text { Age 47, } \\
\text { municipal } \\
\text { officer }\end{array}$ \\
\hline
\end{tabular}

The interviews were semi-structured and related to the preliminary results from the analyses of the meetings. All interviews were held using Zoom. They were recorded and transcribed word-for-word and lasted between 30-60 minutes (IP1 interview lasted 48 minutes, IP2 lasted 56 minutes, IP3 lasted 30 minutes, and IP4 lasted 58 minutes). The interviews give a more qualitative picture of the meetings and will be further analysed in coming papers.

\section{Welcome to the Council Meetings in Oak City and Pine City - Results}

In this section we begin presenting the key characteristics of the two city councils and then proceed with which issues were discussed during the meetings.

\subsection{The Councils of Pine City and Oak City}

Pine City and Oak City are both larger cities in relation to the median local government size in Sweden and they have several similarities as being regional centers, university towns and having a relatively young and growing population.

Pine City is led by the Social Democrats, the Center Party and the Left Party in a coalition. Oak City is led by a coalition consisting of the Moderate Party, Centre Party, the Liberals and the Christian Democrats.

Both cities are large enough to have professional full-time administration of the council. It is the administration who manages the streaming and recording of the council meetings. Both cities also had the capacity and competences to decide and arrange the relevant changes to meet the Covid-19 pandemic constraints. Therefore, the cities are comparable in several ways. The key characteristics of the two analyzed city councils are shown in table 2 .
Table 2: Key characteristics of the two cities

\begin{tabular}{|c|c|c|}
\hline & Oak City & Pine City \\
\hline $\begin{array}{l}\text { Number of } \\
\text { inhabitants } \\
\text { approx. }\end{array}$ & 160000 & 100000 \\
\hline $\begin{array}{l}\text { Number of } \\
\text { members in the } \\
\text { council }\end{array}$ & 79 & 81 \\
\hline $\begin{array}{l}\text { Number of } \\
\text { parties in the } \\
\text { council }\end{array}$ & 8 & 7 \\
\hline $\begin{array}{l}\text { Percentage of } \\
\text { women in the } \\
\text { council }\end{array}$ & 43 & 47 \\
\hline Age group & $\begin{array}{l}\text { Age } \\
\text { mean/median/ } \\
\text { distribution }\end{array}$ & $\begin{array}{l}\text { Age } \\
\text { mean/median/ } \\
\text { age distribution }\end{array}$ \\
\hline $20-70+$ & $48,9 / 47,2$ & $53,5 / 53,6$ \\
\hline $20-29$ & $10,1 \%$ & $6,2 \%$ \\
\hline - $\quad 30-39$ & $21,5 \%$ & $14,8 \%$ \\
\hline $\begin{array}{l}-\quad 40-49\end{array}$ & $25,3 \%$ & $17,3 \%$ \\
\hline $50-59$ & $19,0 \%$ & $23,5 \%$ \\
\hline $60-69$ & $12,7 \%$ & $27,2 \%$ \\
\hline $70+$ & $11,4 \%$ & $11,1 \%$ \\
\hline
\end{tabular}

In both cities we have analyzed two recorded meetings from 2020 and 2021. The meetings in 2020 took place on-site in the city halls and were streamed in a local web channel and saved. The meetings in 2021 took place virtually via Zoom and were also streamed in a local web channel and saved. The analyses are based upon the meetings in January, in between the period when budgets and strategies are debated in both Oak City and Pine City, and most subject matters are rather focuses on issues raised by the council members.

\subsection{Meeting organization in Oak City}

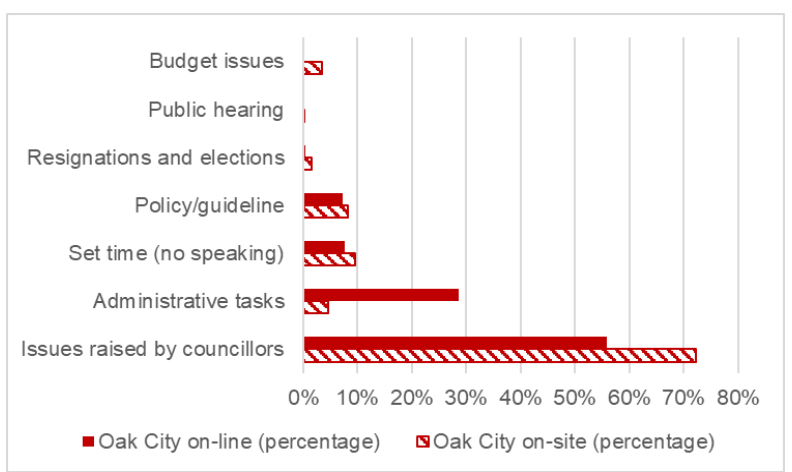

Figure 1 Relative speech duration per type of subject matter on-site and virtual, Oak City

Figure 1 above presents the relative speech duration by different types of subject matters in Oak City. 
Notable is the difference in relative time spent on administrative tasks, including meeting pauses, presence, and information. This observation was further strengthended in the interviews.

\subsection{Meeting Organization in Pine City}

Figure 2 below presents the relative speech duration by different types of subject matters in Pine City. Notable is the increase in time spent on meeting administrative tasks in the virtual meeting and the decrease in relative time spent on issues raised by councilors in the virtual meeting.

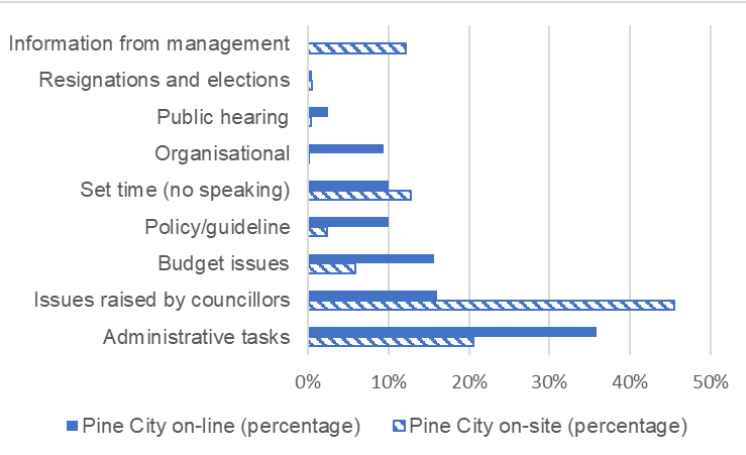

Figure 2 Relative speech duration per type of subject matter on-site and on-line, Pine City

The decrease on time spent on issues raised by councilors may be affected by an agreement that came about between political parties within Pine City and within Oak City to decrease the number of subject matters that cause debate during the pandemic in order to keep meetings short. According to the interviews, these types of subject matters kept filling the pipeline, but did not get put on the council agenda at the same pace in the initial virtual council meetings compared to the later ones in spring 2021. However, after a few virtual meetings the agreements between the political parties in both cities were fully cancelled and the council started to pick up the pace of debating issues raised by councilors to the same extent as before the pandemic, according to the interviews.

\subsection{Comparison of Meeting Organization and Time Use}

This first round of analysis shows that the meeting organization in both cities changed. More time was spent on meeting administration and issues raised by councilors (mostly who is and is not present, general information and pauses).

Notably, but not visualized in the above quantitative analysis, is the change in time spent by the chair to keep the meeting in order when the meeting took place virtually. In this category we included activities such as handling speaking turns and summing up proposals. The chairs may learn how to manage such meeting organization when they become more familiar to the virtual setting of the meeting. But in the meetings observed, it is a notable change of the time use.

These first inductive indications are based on our selection of councils and can be biased in several ways. There are limitations such as local government size, council size, size of the professional organization of the council meetings, the format of recording, among other biases. In spite of this, the data we use here illustrates some key points to discuss and further elaborate on.

\section{Speaking Duration in the Council Meetings}

We found the total meeting duration to be longer in the virtual council meetings compared to the on-site meetings. We also found the total speech duration was longer in the virtual meetings compared to the on-site meetings - 73.9 percent longer in Pine City and 74.1 percent longer in Oak City when compared to the onsite meetings. The chair's share of the total speech duration went from 16.2 percent to 41.8 percent in Pine City and from 10.8 to 17.5 percent in Oak City. Henceforth, we exclude the chairs in the count of total speech duration. The number of speeches in the virtual meeting were higher in both Pine City and Oak City but the average speech duration went down in the virtual meeting by 8 seconds or 11.2 percent in Pine City and by 17 seconds or 19.2 percent in Oak City. In the interviews we asked if the rules on speeches had changed between the on-site and virtual meetings and it was confirmed that no changes had been made in Pine City. However, Oak City had shortened the maximum allowed speech duration from five to three minutes. 


\subsection{Speech Duration in Pine City Council}

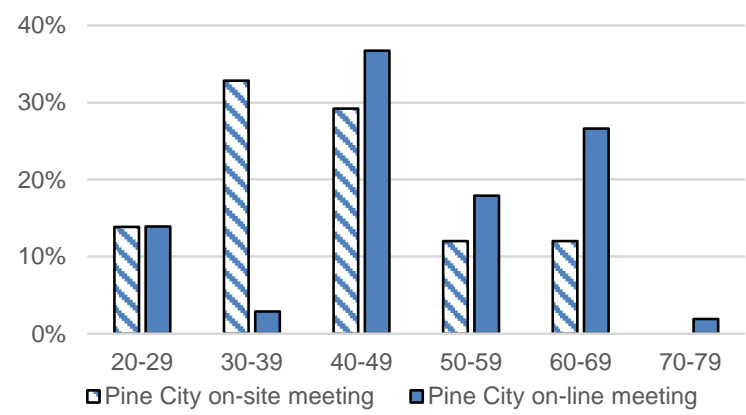

Figure 3 Relative speech duration per age group onsite and on-line in Pine City

Figure 3 above shows the relative speech duration in Pine City for the onsite meeting and the virtual meeting, divided into age groups. Compared to the onsite meeting, relative speech duration was higher in age groups 40 and above in the virtual meeting. The differences in relative speech duration between the onsite meeting and virtual meeting is largest in the age group 30-39. The difference is to some extent effected by one councillor, a "jumper", who stood for 18.3 percent of the total speech duration in the on-site meeting and 18.1 percent of the total speech duration in the virtual meeting. In the interviews, both the chair and secretary in Pine City were asked if they could see any differences in speech duration from different groups in the council when comparing on-site meetings with virtual meetings. Both answered that they perceived it being no different between on-site and virtual council meetings in regard to who spoke and how much [IP1, IP2]. In relation to this question the secretary in Pine City [IP2] mentioned that many of the councillors had previous experience of virtual board meetings.

\section{We have had board meetings that ran digitally. And so, we say more than two-thirds sit on a board. Then they are run into a digital meeting technology and a bit like that. [IP2]}

\subsection{Speech Duration in Oak City Council}

Figure 4 shows the relative speech duration in Oak City for the onsite meeting and the virtual meeting according to age group. Compared to the on-site meeting, relative speech duration was higher in age groups 20-39 and 70-79 in the virtual meeting. The differences in relative speech duration between the onsite meeting and virtual meeting is largest in the age group 20-29. In the interviews, both the chair and secretary in Oak City were asked if they could see any differences in speech duration from different groups comparing on-site and virtual council meetings. They both answered that they could not and that they believed it is still the "usual suspects" who speak the most.

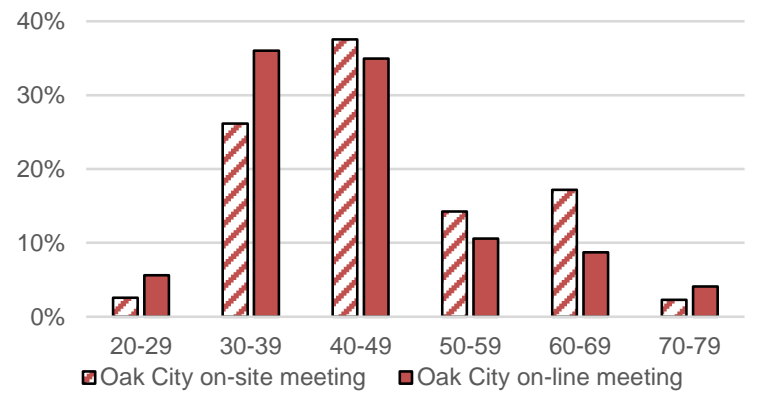

Figure 4 Relative speech duration per age group, onsite and virtual

\section{Concluding Remarks and Openings for Further Research}

The findings presented in this paper are interesting and shed new light on digital democracy during covid19 - the forming a Zoomocracy. Despite the limited number of local councils and meetings included in this study, we are still able to draw some interesting conclusions.

\subsection{Main Conclusions}

In this paper we used an explorative approach to try to make sense of and describe the organization of virtual council meetings in Sweden during the covid19 pandemic. We argue that the meeting format matters for who takes the floor at a council meeting. The main conclusion from this analysis is that virtual council meetings may lead to changes in speech duration, meeting length and balances among different age groups compared to on-site meetings. However, our study is limited in the sense that we have only four meetings in two local government councils out of 310 local governments in Sweden. This makes it hard to generalize the results both within the contextual setting of each council and beyond to the local government and Swedish context.

Our aim with this study was partly to contribute to knowledge on virtual council meetings in Sweden and partly to develop a method for continued research on this topic. We want to emphasize the latter and that we are continuing our research, adding more local government meetings to refine our method. The main 
tentative hypotheses we had that younger councilors would use more speech time could not be confirmed here. An initially planned gender analysis was excluded since speech duration could instead be explained by which issues where on the agenda and specific commitment in certain issues presented too much bias. In coming studies with larger numbers of meetings this will be addressed and tested again.

Besides speech duration, we coded speeches with regard to the speaker's rhetoric, appearance, the speaker's environment (office, bedroom, kitchen etc.), and body language. There is a wealth of data there, of which we have only begun to scratch the surface of in analyzing the meetings using these variables. However, in the interviews with the chairs and secretaries, we did discuss some of our preliminary observations. For instance, there was a broad consensus amongst researchers and the inter-viewed about body language in virtual council meetings being more subtle compared to on-site meetings, where councilors speak from a podium facing the council. Observations on councilors not being able to adapt to the technical standards of virtual meetings, such as being inside the camera angles when speaking, was also discussed and supported by the interviewed. The overall impression from watching the recorded virtual meetings was that many councilors have indeed adapted well to the virtual environment whilst others have not. We need to further develop our understanding of how digital competences and digital leadership in the councils affects the democratic meeting procedure. Doing so would contribute to developing digital leadership, digital competences, and regulations of virtual meetings towards supporting a more democratic "Zoomocracy".

\subsection{Reflections on the Research Design}

The methodological approach in this study can be described as a creative and explorative case study using both qualitative and quantitative text analysis. There is further reason to highlight and discuss meeting duration as a measure. The data was collected using both semi-structured interviews and by analyzing recorded videos of council meetings in two different local governments before and during the covid-19 pandemic. Analysis of video recordings in contrast to written protocols gives us the opportunity to analyze speech duration and rhetorical aspects of meeting activity across meetings.

Both inductive and deductive reasoning took place in planning and executing the study. In the planning phase, the researchers reasoned with each other against the backdrop of our previous studies, theories, and experiences on virtual meetings. The reasoning amongst the authors of this paper continued through the collection of data. Parts of the preliminary findings were also discussed with the interviewees and subject matter experts within SALAR, which influenced our processing and analysis of data.

\subsection{Reflections on the Research Design and Potential Development of the Study}

We can see developments of this type of research occurring along several lines besides a larger sample of meetings. There is a need to further develop research and understanding of speech duration, speech frequency and other rhetorical aspects of meetings.

The organization of the meetings and the use of technology can be further addressed. This would help to improve the meetings and the interactive formats. We can also see a need to develop complementary programs for encouraging discussions and more transparent decision making.

We remain interested in examining the impact of age and gender and any possible gender-generation effects [28]. Age and gender were proposed both in the interviews and our former studies [20] and could be considered textbook level statements on democratic inclusion and participation.

The long-term effects of the meetings will be interesting to follow and to see any potential learning resulting among councilors as well as management of the meetings.

\section{References}

[1] S. Matteo, M. Santo, H. John, F.M. Enrique, B. Martina, "Teleworkability and the COVID-19 crisis: a new digital divide?", In: Joint Research Centre (Seville site), 2020. Accessed 2021-06-14.

https://www.econstor.eu/handle/10419/231337\#

[2] P. Hall, "Offentligt ledarskap och möten" s. 149-175 in T. Bergström and N. Eklund (eds), Ett annorlunda ledarskap: chef i politiskt styrd verksamhet, Lund, Studentlitteratur, 2019.

[3] A.Tschentscher, A. Bächtiger, J. Steiner, M. Steenbergen, "Deliberation in parliaments research objectives and preliminary results of the Bern center for interdisciplinary deliberation studies (bids). Legisprudence: International Journal for the Study of Legislation, 4(1), pp. 13-34, 2010.

[4] J. Fishkin, Toward a deliberative democracy: experimenting with an ideal. Citizen competence and democratic institutions, pp. 279-90, 1999.

[5] Marcinkiewicz, K and Stegmaier, M, Speaking up to stay in parliament: the electoral importance of speeches and other parliamentary activities. The Journal of Legislative Studies, 25(4), 576-596, 2019. 
[6] H. Baldersheim and H. Wollmann, (Eds.), The comparative study of local government and politics: overview and synthesis. Barbara Budrich Publisching, Leverkusen Opladen, 2006.

[7] G. Ó. Erlingsson and J. Wänström, Politik och förvaltning i svenska kommuner. Studentlitteratur AB, Lund, 2015.

[8] SALAR. Medborgardialog och medborgarförslag erfarenheter av medborgardialog och medborgarförslag i kommuner, landsting och regioner. (Citizens dialog and citizens proposals - Experiences from citizen dialog fora.) Stockholm: Sveriges Kommuner och Landsting, 2014. Access: 2021-06-09. http://webbutik.skl.se/bilder/artiklar/pdf/7585-2645.pdf?issuusl=ignore.

[9] A. Lidström and T. Madell, "Local Government in Sweden”, Local Self-Government in Europe / [ed] Boštjan Brezovnik, Istvan Hoffman, Jarosław Kostrubiec, Lex Localies Press, Maribor, pp. 415-433, 2021.

[10] G. Ó. Erlingsson and J. Ödalen, ”A Normative Theory of Local Government: Connecting Individual Autonomy and Local Self-Determination with Democracy". Lex Localis-Journal of Local SelfGovernment, 15(2), pp. 329-342, 2007.

[11] C. Copus and G. O. Erlingsson, "Parties in local government: A review". Representation, 48(2), pp.235-247, 2012.

[12] J. Högström, "Does closeness matter for voter turnout in proportional systems? An examination at the local level in Sweden. European Political Science, 17, pp. 571-586, 2018.

[13] Lidström, A, "Various faces of localised voting in Sweden”. Local Government Studies, 47(1), 126-144, 2021.

[14] SCB 2021. Statistikdatabas. https://kommunsiffror.scb.se/?id1=2281\&id2=0580.

[15] S. Montin and M. Granberg, Moderna kommuner. Stockholm, Liber, 2013.

[16] "Vital kommunal demokrati: betänkande". Stockholm: Fritze. 2012.

[17] SALAR. Politiska möten i kommuner och regioner under 2020. (Political meetings in local and regional governments during 2020). Stockholm: Sveriges Kommuner och Regioner. 2021. Access: 2021-06-09. https://webbutik.skr.se/bilder/artiklar/pdf/7585-9224.pdf?issuusl=ignore

[18] "En kommunallag för framtiden: slutbetänkande". Stockholm: Fritze, 2015.

[19] "Låt fler forma framtiden!: betänkande". Stockholm: Wolters Kluwer, 2016.

[20] F. Carlsson, H. Iacobaeus, E. Wihlborg, "Democratic decisions during Covid-19 - digital tools for adaption". Statsvetenskaplig tidskrift. 123 (5), pp. 431-449, 2021.

[21] A. Kulanovic, F. Carlsson, E. Wihlborg, 'Local leadership for public digital transformation towards smart cities - Reflections from leaders." Paper presented at the Conferance paper presented at EGOV, Linköping 2020-08-31 - 2020-09-02, pp. 145-154, 2020.
[22] P. Klapka, K. Ellegård and B. Frantál, "What about Time-Geography in the post-Covid-19 era?". Moravian Geographical Reports. Dec 1;28(4), pp. 23847, 2020.

[23] J. van Dijk and K. Hacker, "The Digital Divid as a Complex and Dynamic Phenomenon". The Information Society, 19(4), pp. 315-326, 2011.

[24] L. Borghans, B. ter Weel, "Do older workers have more trouble using a computer than younger workers?" In A. de Grip, J. van Loo, \& K. Mayhew (Eds.), The Economics of Skills Obsolescence. pp. 139-173. Emerald Group Publishing Limited, 2002.

[25] E. Amnå and J. Ekman, "Standby citizens: diverse faces of political passivity". European Political Science Review, 6(2), pp. 261-281, 2014.

[26] J. Miles and M. Shevlin. Applying regression \& correlation: a guide for students and researchers. SAGE, London, 2001.

[27] N.W.H. Blaikie, Designing social research: the logic of anticipation. (2. ed.) Polity, Cambridge, 2009.

[28] Segaard, S. B and Saglie, J, A gender-generation gap in political representation? The contingent impact of preference voting in Norwegian municipal elections. Local Government Studies, 47(1), 145-165, 2021. 